\title{
PENGGUNAAN ROC PADA SKRINING PRE-EKLAMPSIA DENGAN METODE USG DVAUT PADA IBU HAMIL DI PUSKESMAS MULYOREJO SURABAYA
}

\author{
ROC USE ON SCREENING PREECLAMPSIA USING USG DVAUT \\ METHOD IN PREGNANT WOMEN IN MULYOREJO PRIMARY HEALTH \\ CENTER SURABAYA
}

\author{
Intan Laraswati ${ }^{1}$, Diah Indriani ${ }^{2}$ \\ 1,2Departemen Biostatistika dan Kependudukan \\ Fakultas Kesehatan Masyarakat Universitas Airlangga \\ Jl. Mulyorejo Kampus C Unair Surabaya, Jawa Timur 60115, Indonesia \\ Alamat korespondensi: Intan Laraswati \\ E-mail: missintanlaras@gmail.com
}

\begin{abstract}
Pre-eclampsia is the third highest cause of death in pregnant women. Symptoms of pre-eclampsia can be identified by the presence of hypertension, proteinuria and edema during pregnancy until postpartum. Pre-eclampsia cannot be identified with certain risk factors, and cannot be prevented. Pre-eclampsia can be detected early using the preeclampsia screening method with sonography. The sonographic device used is referred to as DVAUt ultrasound (Uterine Artery Doppler Velocimetry Ultrasonography). This studying an analytic observational research with a cross sectional study design. The population was all pregnant women who examined at the Mulyorejo primary health center in 2013 until the first quarter of 2018. The sampling technique was consecutive sampling with inclusion and exclusion criteria. The number of samples obtained is 496 data. The study aimed to determine the sensitivity and specificity of the pre-eclampsia screening method using DVAUt ultrasound in detecting the tendency of pregnant women to experience pre-eclampsia. The data were analyzed of sensitivity and specificity and the Receiver Operating Characteristic (ROC) curve with $p<0.001$. P1GF / sFlt-1 (Gold standard) biomaker test sensitivity of $89 \%$ and specificity of $90 \%$. The results of this study were the sensitivity of pre-eclampsia screening at $99.7 \%$ and specificity of $81.9 \%$. The ROC method obtained the results of pre-eclampsia screening using DVAUt ultrasound has a high sensitivity and specificity in detecting the tendency of pregnant women to experience preeclampsia. Suggestions for research to refresh knowledge and procedures for conducting pre-eclampsia screening checks.
\end{abstract}

Keywords: pre-eclampsia screening, sensitivity, specificity, receiver operating characteristic

\begin{abstract}
ABSTRAK
Pre-eklampsia menjadi penyebab kematian tertinggi ketiga pada ibu hamil. Gejala pre-eklampsia dapat dikenali dengan adanya hipertensi, proteinuria serta edema selama kehamilan sampai dengan postpartum. Pre-eklampsia tidak dapat diketahui secara pasti faktor risikonya, serta tidak dapat dicegah. Pre-eklampsia pada ibu hamil dapat dideteksi secara dini menggunakan metode skrining pre-eklampsia dengan alat sonografi. Alat sonografi yang digunakan disebut sebagai USG DVAUt (Ultrasonografi Doppler Velocimetry Arteri Uterina). Penelitian ini termasuk dalam penelitian observasional analitik dengan rancangan penelitian cross sectional. Populasi penelitian adalah semua ibu hamil yang periksa di Puskesmas Mulyorejo tahun 2013 sampai tribulan pertama tahun 2018. Teknik sampling adalah consecutive sampling dengan kriteria inklusi dan eksklusi. Jumlah sampling yang diperoleh sebesar 496 data. Penelitian bertujuan untuk mengetahui sensitivitas dan spesifisitas metode skrining pre-eklampsia menggunakan USG DVAUt dalam mendeteksi kecenderungan ibu hamil mengalami pre-eklampsia. Penelitian diolah dengan analisis sensitivitas dan spesifisitas serta kurva ROC (Receiver Operating Characteristic) dengan $\mathrm{p}$ $<0,001$. Tes biomaker P1GF/sFlt-1 (Gold standard) sensitivitas $89 \%$ dan spesifisitas $90 \%$. Hasil penelitian adalah sensitivitas skrining pre-eklampsia sebesar $99,7 \%$ dan spesifisitas sebesar $81,9 \%$. Metode ROC mendapatkan hasil skrining pre-eklampsia menggunakan USG DVAUt memiliki sensitivitas dan spesifisitas yang tinggi dalam mendeteksi
\end{abstract}


kecenderungan ibu hamil mengalami pre-eklampsia. Saran penelitian untuk melakukan refreshing pengetahuan serta tatacara melakukan pemeriksaan skrining pre-eklampsia.

Kata kunci: skrining pre-eklampsia, sensitivitas, spesifisitas, receiver operating characteristic

\section{PENDAHULUAN}

Receiver Operating Characteristic (ROC) memiliki pengertian sebagai kurva yang digunakan untuk mendefinisikan sensitivitas dan spesifisitas serta untuk menemukan nilai titik potong tertentu. Menurut Dahlan (2009), sensitivitas adalah kemampuan diagnosis benar pada pasien sakit. Spesifisitas adalah kemampuan diagnosis benar pada pasien yang tidak sakit (Budiarto, 2012). Sensitivitas dan spesifisitas berguna untuk mengukur kemampuan alat atau diagnosis dalam mendeteksi penyakit pada pasien.

Kurva ROC adalah suatu cara untuk menafsirkan nilai sensitivitas dan spesifisitas serta menemukan titik potongnya. Kurva ROC adalah generalisasi dari serangkaian kombinasi potensial antara sensitivitas dan spesifisitas yang dapat menjadi prediktor. Analisis kurva ROC memiliki informasi tentang titik potong, serta memberikan skala umum alami untuk membandingkan prediktor berbeda yang diukur dalam unit berbeda (Pepe et al., 2004).

Receiver Operating Characteristic (ROC) Curve dapat digunakan untuk melakukan deteksi dini atau uji diagnosis (screening test) yang berkelanjutan atau memiliki lebih dari dua jenis uji. Dari ROC ini bisa diperoleh nilai Area Under the Curve (AUC). AUC bisa dipergunakan untuk menilai keakuratan suatu diagnosis. AUC adalah luas area yang berada di bawah garis ROC. AUC memiliki nilai pada rentang 50\% sampai dengan $100 \%$. Arti nilai $50 \%$ pada AUC berarti nilai yang kurang baik. Nilai mendekati $100 \%$ berarti baik, yaitu diagnostik yang dilakukan pada pasien memberikan hasil yang benar ada tidaknya suatu penyakit pada pasien.

Kehamilan adalah hal alamiah terjadi pada wanita diseluruh dunia. Namun, kehamilan tidak selalu dialami semua wanita dengan lancar dan mudah. Ibu hamil dapat mengalami berbagai macam pemberat selama proses kehamilan, persalinan hingga masa nifas atau postpartum. Pemberat atau penyulit selama proses kehamilan sampai dengan masa nifas dapat menyebabkan ancaman pada kondisi kesehatan ibu maupun janin yang dikandungnya. Ancaman kesehatan ini dapat berujung pada terjadinya kematian ibu hamil maupun janin.

Penyebab terbanyak kematian ibu, yaitu perdarahan, infeksi, pre-eklampsia, persalinan lama dan aborsi (Prawirohardjo, 2013). Jumlah kematian ibu yang disebabkan pre-eklampsia sebesar 17\% di Asia Tenggara sedangkan di Indonesia sebesar 25\% (Kemenkes RI, 2014b). Jumlah kematian ibu bersalin dengan penyebab pre-eklampsia di Jawa Timur pada tahun 2012 sebanyak 18 orang. Jumlah Angka Kematian Ibu pada tahun 2017 adalah 91,92 orang per 100.000 kelahiran hidup (Dinkes Provinsi Jawa Timur, 2018). Kematian ibu yang terjadi di Puskesmas Mulyorjeo adalah jumlah kematian ibu terbanyak yang terjadi pada tahun 2012 yaitu sejumlah dua orang sedangkan pada 2017 tidak ada kematian ibu. Persentase kasus pre-eklampsia yang terjadi di wilayah kerja Puskesmas Mulyorejo dari tahun 2013 sampai dengan tahun 2018 per 1000 kelahiran hidup, yaitu pada tahun 2013 sebesar $1,27 \%$, pada tahun 2014 sebesar $0,86 \%$, pada tahun 2015 sebesar $0,77 \%$, pada tahun 2016 sebesar $0,98 \%$, tahun 2017 sebesar $0,90 \%$ dan tribulan pertama tahun 2018 sebesar 0,86\%.

Pre-eklampsia atau disebut juga sebagai pregnancy-specific syndrome adalah jenis Pregnancy Induced Hypertension (PIH) karena hanya timbul pada masa kehamilan dan diatasi dengan dilakukan tindakan terminasi kehamilan. Pre-eklampsia diartikan sebagai tekanan darah (hipertensi) yang mulai meningkat setelah umur kehamilan 20 minggu diikuti oleh tanda proteinuria maupun bengkak pada tungkai atas atau bawah.

Tekanan darah tinggi (hipertensi) dapat diartikan sebagai meningkatnya tekanan darah 
sistolik > $140 \mathrm{mmHg}$ dan tekanan darah diastolik $>90 \mathrm{mmHg}$ pada dua kali pengukuran memiliki jarak waktu lima menit (Kemenkes RI, 2014a). Macam hipertensi dibedakan dari klasifikasi hipertensi, yaitu hipertensi diastolik (diastolic hypertension), hipertensi campuran (sistolik dan diastolik meninggi), hipertensi sistolik (isolated systolic hypertension). Hipertensi memiliki jenis lain, yaitu hipertensi pulmonal dan hipertensi pada kahamilan. Hipertensi dalam kehamilan terbagi dalam beberapa jenis, yaitu preeklampsiaeklampsia, hipertensi kronik, preeklampsia pada hipertensi kronik, hipertensi gestational (Kemenkes RI, 2014).

Dampak pre-eklampsia yang tidak tertangani adalah eklampsia atau kejang. Kejang pada ibu hamil dapat mengakibatkan kematian ibu maupun janin. Pre-eklampsia termasuk penyumbang Angka Kematian Ibu (AKI) yang cukup besar. AKI melahirkan belum memenuhi target yang diharapkan. Konsep Sustainable Development Goals (SDG) yang memiliki arti sebagai Tujuan Pembangunan Berkelanjutan 2030 atau Global Goals yang dirumuskan di Jakarta pada tanggal 1 Desember 2015 merupakan rencana program jangka panjang yang dimiliki oleh pemerintah Indonesia. Kementerian Kesehatan Republik Indonesia menyatakan persetujuan terhadap 17 poin tujuan SDGs. Bidang kesehatan dalam kerangka SDGs menjadi perhatian khusus bagi pemerintah. Poin tersebut berada pada urutan ketiga tentang Good Health and Well-being atau kesehatan yang paripurna. Angka kematian ibu berkurang dengan jumlah dibawah 70 per 100.000 kelahiran hidup adalah isi salah satu poin nomor tiga dalam SDGs (Panuluh \& Fitri, 2016).

Salah satu cara untuk mengatasi masalah kematian ibu dengan penyebab pre-eklampsia perlu diadakannya program percepatan penurunan angka kematian ibu dengan penyebab pre-eklampsia yang melibatkan pihak tenaga kesehatan. Ibu hamil yang datang untuk Antenatal Care (ANC) dilakukan pemeriksaan deteksi dini pre-eklampsia serta di monitoring hasilnya selama kehamilan. Monitoring ibu hamil selama ANC dilakukan secara kontinu dalam masa kehamilan hingga persalinan. Deteksi dini atau skrining pre-eklampsia adalah cara yang dipilih untuk mencegah kematian ibu secara dini. Deteksi dini atau skrining pre-eklampsia dilakukan dengan alat sonografi. Alat sonografi atau yang disebut dengan Ultrasonografi Doppler Velocimetry Artery Uterine (USG DVAUt). Untuk mengetahui bagaimana sensitivitas dan spesifisitas skrining pre-eklampsia yang dilakukan pada ibu hamil yang berkunjung di Puskesmas Mulyorejo digunakan metode Receiver Operating Characteristic (ROC) Curve.

Penelitian ini bertujuan untuk mengetahui sensitivitas dan spesifisitas skrining pre-eklampsia menggunakan USG DVAUt yang dilakukan pada ibu hamil di Puskesmas Mulyorejo. Penelitian akan memunculkan gambar kurva ROC dan nilai Area Under Curve (AUC).

\section{METODE PENELITIAN}

Penelitian "Penggunaan ROC pada Skrining Pre-eklampsia dengan USG DVAUt pada Ibu Hamil" termasuk dalam penelitian observasional analitik dengan rancangan penelitian cross sectional. Populasi penelitian adalah semua ibu hamil yang melakukan pemeriksaan di Puskesmas Mulyorejo pada tahun 2013 sampai tribulan pertama tahun 2018. Teknik sampling yang digunakan adalah consecutive sampling dengan kriteria inklusi dan eksklusi. Kriteria inklusi sebagai berikut ibu hamil dengan usia kehamilan 13-24 minggu yang mengikuti pemeriksaan USG DVAUt. Kriteria eksklusi yaitu ibu hamil yang memiliki faktor risiko hipertensi. Jumlah sampling yang diperoleh sebesar 496 data. Pengumpulan data menggunakan lembar pengumpulan data laporan skrining pemeriksaan ibu hamil. Lembar pengumpulan data skrining ibu hamil terdiri dari kolom nama ibu hamil, usia, berat badan, tinggi badan, hasil pengukuran tekanan darah terlentang dan miring, hasil pemeriksaan USG DVAUt. Data yang diperoleh dari pengumpulan data kemudian dilakukan editing, coding, entry data ke dalam SPSS, verifikasi data sekunder, pengolahan data sekunder. Data sekunder yang telah diolah dengan SPSS metode ROC $\mathrm{p}<0,001$, dilakukan pembacaan hasil metode ROC.

Lokasi penelitian adalah Puskesmas Mulyorejo. Waktu penelitian mulai bulan 
September 2018 sampai dengan November 2018. Variabel bebas (independent variable) pada penelitian adalah hasil skrining pre-eklampsia ibu hamil dengan pemeriksaan USG DVAUt. Variabel terikat (dependent variable) adalah hasil interpretasi pemeriksaan skrining pre-eklampsia pada ibu hamil.

Penelitian ini adalah penelitian uji diagnostik. Penelitian uji diagnostik adalah penelitian bertujuan menguji keakuratan suatu alat diagnostik dengan membandingkan hasil pemeriksaan menggunakan suatu alat diagnostik, yaitu skrining pre-eklampsia dengan USG DVAUt. Selanjutnya data yang diperoleh diolah dan dianalisis menggunakan metode Receiver Operating Characteristic (ROC) bertujuan mendapatkan nilai Area Under Curve (AUC) dari alat diagnostik yang diuji. Kemudian pada kurva AUC dilakukan pencarian titik potong yang paling baik diolah untuk mendapatkan sensitivitas dan spesifisitas alat diagnostik. Titik potong ditentukan secara statistik. Cara penentuan ini dipilih jika penentuan titik potong secara klinis sulit dilakukan. Program yang digunakan adalah Microsoft Office Excel. Program tersebut memiliki hasil titik potong optimal dilihat dari keseimbangan sensitivitas dan spesifisitas (Dahlan, 2009).

\section{HASIL PENELITIAN}

Hasil penelitian "penggunaan ROC pada skrining pre-eklampsia dengan USG DVAUt pada ibu hamil di Puskesmas Mulyorejo Surabaya" pada Tabel 1, Tabel 2, Tabel 3, Tabel 4 dan Gambar 1.

Tabel hasil perhitungan data pada program SPSS dengan metode ROC menunjukkan bahwa jumlah subjek ibu hamil dengan kecenderungan

Tabel 1. Hasil Perhitungan Data pada Program SPSS dengan Metode ROC

\begin{tabular}{lcc}
\hline $\begin{array}{l}\text { Hasil Skrining } \\
\text { Pre-Eklampsia }\end{array}$ & Valid N & $\begin{array}{c}\text { Persentase } \\
(\%)\end{array}$ \\
\hline Positif & 319 & 64,31 \\
Negatif & 177 & 35,69 \\
\hline Total & 496 & 100 \\
\hline
\end{tabular}

Tabel 2. Tabel $2 \times 2$ Hasil Pemeriksaan Skrining Pre-eklampsia USG DVAUt pada Ibu Hamil di Puskesmas Mulyorejo

\begin{tabular}{lccc}
\hline \multirow{2}{*}{$\begin{array}{l}\text { Skrining PE } \\
\text { USG DVAUt }\end{array}$} & Sakit & $\begin{array}{c}\text { Tidak } \\
\text { Sakit }\end{array}$ & Total \\
\cline { 2 - 3 } & 145 & 1 & 146 \\
\hline Positif & 32 & 318 & 350 \\
Negatif & 177 & 319 & 496 \\
\hline Total & &
\end{tabular}

Tabel 3. Area Under the Curve Skrining Pre-eklampsia menggunakan USG DVAUt pada Ibu Hamil di Puskesmas Mulyorejo Surabaya

\begin{tabular}{ccccc}
\hline \multirow{2}{*}{ Area Std eror } & $\begin{array}{c}\text { Asymptotic } \\
\text { sig. }\end{array}$ & \multicolumn{2}{c}{$\begin{array}{c}\text { Asymptotic 95\% } \\
\text { Confidence Interval }\end{array}$} \\
\cline { 3 - 5 } & & $\begin{array}{c}\text { Lower } \\
\text { Bound }\end{array}$ & Upperbound \\
\hline 0,908 & 0,017 & 0,000 & 0,874 & 0,942 \\
\hline
\end{tabular}

Tabel 4. Coordinates of the Curve Skrining Pre-Eklampsia Menggunakan USG DVAUt pada Ibu Hamil di Puskesmas Mulyorejo Surabaya

\begin{tabular}{cccc}
\hline $\mathbf{p}$ & Sensitivitas & 1-Spesifisitas & Spesifisitas \\
\hline 0,00 & 0,000 & 0,000 & 1 \\
1,50 & 0,997 & 0,181 & 0,819 \\
3,00 & 1,000 & 1,000 & 0,000 \\
\hline
\end{tabular}

pre-eklampsia adalah 319 data dari 496 jumlah total data. Prevalensi kecenderungan preeklampsia sebesar $64,31 \%$. Jumlah subjek ibu hamil yang tidak memiliki kecenderungan preeklampsia sebesar 177 data dari 496 jumlah total data.

Tabel $2 \times 2$ hasil pemeriksaan skrining pre-eklampsia USG DVAUt pada ibu hamil di Puskesmas Mulyorejo menunjukkan bahwa ibu hamil dengan hasil skrining positif pre-eklampsia dan mengalami pre-eklampsia sejumlah 145 orang. Ibu hamil dengan hasil skrining preeklampsia negatif dan tidak mengalami preeklampsia sejumlah 318 orang. 


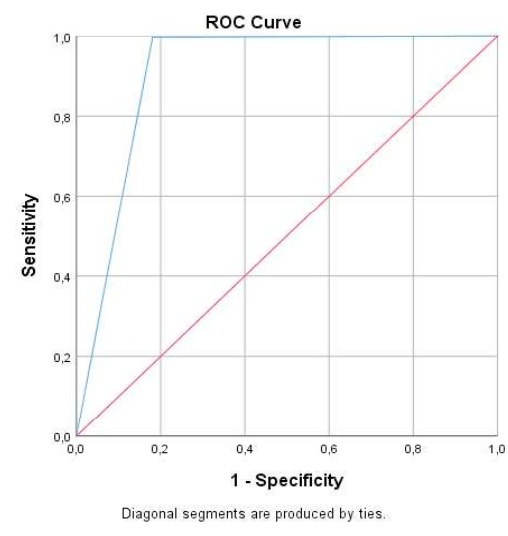

Gambar 1. Kurva ROC Skrining Pre-eklampsia menggunakan USG Dvaut pada Ibu Hamil di Puskesmas Mulyorejo Surabaya

Keterangan:Garis Biru adalah hasil skrining preeklampsia menggunakan metode USG DVAUt pada ibu hamil. Garis Merah adalah reference line.

Kurva ROC sebagai output penelitian menunjukkan bahwa nilai kecenderungan preeklampsia memiliki nilai diagnostik yang baik karena kurva hasil skrining pre-eklampsia menggunakan USG DVAUt pada ibu hamil jauh dari angka 50\% dan mendekati angka 100\%.

Nilai Area Under Curves (AUC) yang diperoleh dari metode ROC sebesar $90,8 \%$ (95\% IK 87,4\% - 94,2\%), p < 0,001. Nilai AUC sebesar 90,8\% tergolong kuat berdasarkan statistik. Nilai AUC sebesar 90,8\% memiliki arti bahwa skrining pre-eklampsia menggunakan USG DVAUt dilakukan untuk mendiagnosis kecenderungan pre-eklampsia pada $100 \mathrm{ibu}$ hamil, maka kesimpulan yang tepat akan diperoleh pada $90 \mathrm{ibu}$ hamil. Interval kepercayaan (IK) menunjukkan bahwa apabila AUC skrining pre-eklampsia pada populasi data rekap skrining pre-eklampsia ibu hamil berkisar antara $87,4 \%$ sampai dengan $94,2 \%$. Nilai AUC sebesar $94,2 \%$ dianggap sangat memuaskan bagi peneliti karena lebih besar dari nilai AUC yang diharapkan yaitu sebesar $50 \%$.

Tabel Coordinates of the Curves skrining pre-eklampsia menggunakan USG DVAUt pada ibu hamil di Puskesmas Mulyorejo Surabaya menunjukkan bahwa hasil sensitivitas skrining pre-eklampsia menggunakan USG DVAUt sebesar 99,7\%. Sedangkan hasil spesifisitas skrining pre-eklampsia menggunakan USG DVAUt sebesar $81,9 \%$.

\section{PEMBAHASAN}

Pre-eklampsia adalah penyakit yang muncul ditandai dengan hipertensi, proteinuria dan edema selama kehamilan, persalinan sampai dengan masa nifas. Pre-eklampsia atau disebut juga dengan Pregnancy Induced Hipertension (PIH) gestosis atau keracunan kehamilan (Maryunani \& Yulianingsih, 2012). Pre-eklampsia biasa terjadi pada tribulan ketiga kehamilan, tetapi dapat pula terjadi lebih awal, misalnya pada mola hidatidosa (Abdul, 2006).

Faktor risiko pre-eklampsia belum ditemukan pasti dalam teori, tapi beberapa penelitian merumuskan beberapa faktor yang mempengaruhi terjadinya pre-eklampsia. Faktor risiko penyebab pre-eklampsia diantaranya, yaitu riwayat pre-eklampsia, primigravida, kegemukan, kehamilan ganda, riwayat penyakit tertentu (hipertensi kronik, diabetes, penyakit ginjal, reumatik arthritis atau lupus, hipertiroid), kehamilan mola, antenatal care tidak teratur, psikologis, pola nutrisi.

Komplikasi pre-eklampsia pada ibu adalah kematian, iskemia otak atau perdarahan, kejang, defisiensi neurologis jangka panjang, edema paru atau gagal jantung kongestif, aspirasi pnemonia, miokardial iskemia atau aritmia ventrikel (Doenges, Moorhouse dan Geissler, 2012), iskemia hati atau perdarahan, gagal ginjal akut, abruptio plasenta atau koagulasi intravaskular diseminata (The Society of Obstetricians and Gynaecologists of Canada, 2016). Komplikasi pada janin adalah kematian janin, pertumbuhan janin yang terhambat, hipoksia atau asidosis, kelahiran prematur (Putra, Hasibuan dan Fitriyati, 2016), penyakit degereneratif yaitu hipertensi, diabetes melitus, penyakit jantung (Sibai, 2013).

Skrining pre-eklampsia untuk mengevaluasi faktor risiko pre-eklampsia tidak dianjurkan dilakukan (The American College of Obstetricians and Gynecologists, 2013). Preeklampsia pada ibu hamil dapat dideteksi secara dini menggunakan alat ultrasonografi yang biasa 
disebut dengan pemeriksaan Ultrasonografi Doppler Velocimetry Artery Uterina (USG DVAUt). Penggunaan studi uji diagnostik skrining pre-eklampsia USG DVAUt dalam evaluasi dan manajemen kehamilan yang rumit oleh dugaan terhambatnya pertumbuhan janin dan isoimunisasi sel darah merah untuk memantau terapi intrauterin dan persalinan. Uji diagnostik skrining pre-eklampsia USG DVAUt yang paling sering dinilai dari janin adalah arteri umbilikalis dan arteri serebral tengah (MCA). Uji diagnostik skrining pre-eklampsia USG DVAUt dari MCA digunakan dalam penilaian janin yang berisiko dengan ibu hamil anemia dan janin yang mengalami restorasi. Uji diagnostik skrining preeklampsia USG DVAUt arteri umbilikalis dapat mencerminkan kelainan pada sisi janin dengan resistensi plasenta dan penilaian pembuluh darah ibu dengan mengevaluasi aliran darah atau sisi ibu dari resistensi plasenta (Sciscione \& Hayes, 2009). Hal ini sesuai dengan hasil penelitian yang menunjukkan hasil tinggi untuk sensitivitas dan spesifitas alat USG DVAUt. Sensitivitas dan spesifisitas tinggi berarti tes USG DVAUt adalah tes diagnostik yang valid dalam mendeteksi kecenderungan seorang ibu hamil mengalami preeklampsia. Untuk saat ini, metode yang banyak digunakan dalam pendeteksian pre-eklampsia adalah menggunakan alat USG DVAUt. USG DVAUt dianggap sebagai alat diagnostik yang efektif dan efisien dalam mendeteksi pre-eklampsia secara dini serta mendapatkan penanganan awal bagi ibu hamil yang terdeteksi memiliki kecenderungan pre-eklampsia.

Sensitivitas dan spesifisitas skrining preeklampsia menggunakan USG DVAUt tinggi karena USG DVAUt adalah metode non-invasif yang digunakan untuk skrining pre-eklampsia selama lebih dari 20 tahun. Faktor dari ibu hamil itu sendiri juga ikut mempengaruhi hasil pemeriksaan skrining pre-eklampsia. Ibu hamil yang terdeteksi positif kecenderungan preeklampsia saat skrining, dapat tidak menjadi pre-eklampsia, begitu juga sebaliknya, ibu hamil yang terdeteksi negatif kecenderungan preeklampsia dapat menjadi pre-eklampsia. Faktor yang dapat mempengaruhi diantaranya yaitu konsumsi kalsium dosis tinggi, menjaga pola hidup sehat dengan memakan makanan bergizi seimbang, istirahat cukup serta menghindari stres. Faktor psikologis ibu hamil juga berpengaruh terhadap pre-eklampsia. Ibu hamil yang kurang mendapat dukungan keluarga dapat mengalami stres sehingga timbul pre-eklampsia.

Skrining pre-eklampsia sebaiknya dilakukan pada usia kehamilan trimester kedua untuk mendapatkan hasil pemeriksaan skrining preeklampsia dengan menggunakan USG DVAUt (Antsaklis \& Daskalakis, 2010). Hal ini sesuai dengan data yang digunakan dalam penelitian adalah data kunjungan ibu hamil yang berada pada trimester kedua kehamilan. Oleh karena itu, diperlukan keteraturan dalam melakukan pemeriksaan kehamilan atau Antenatal Care (ANC) sehingga petugas dapat memantau perkembangan kehamilan serta melakukan pemeriksaan skrining kehamilan sesuai dengan usia kehamilan yang tepat. Sesuai dengan teori bahwa ANC adalah pengawasan sebelum persalinan terutama pada pertumbuhan dan perkembangan janin serta mengoptimalkan kesehatan mental dan fisik ibu hamil, sehingga ibu hamil mampu mengenali tanda bahaya kehamilan (Depkes RI, 2006). Ibu hamil yang teratur melakukan ANC memiliki kemampuan deteksi dini yang lebih baik daripada ibu hamil yang tidak teratur melakukan ANC (Dewi, Sulistiyono dan Mahmudah, 2015). Pemeriksaan skrining pre-eklampsia yang dilakukan pada usia kehamilan yang tidak tepat dikhawatirkan akan mendapatkan hasil pemeriksaan yang kurang akurat dan menyebabkan kekurang tepatan dalam pemberian penanganan pada ibu hamil yang seharusnya mendapat penanganan awal pre-eklampsia. Skrining pre-eklampsia yang dilakukan pada usia kehamilan trimester ketiga dikhawatirkan tidak dapat memunculkan hasil yang kurang akurat dikarenakan pembuluh darah ibu sudah tertutup uterus yang semakin membesar (Sciscione \& Hayes, 2009).

Skrining pre-eklampsia USG DVAUt memiliki kelebihan salah satunya adalah hasil pemeriksaan yang didapatkan lebih akurat. Hasil pemeriksaan dengan USG DVAUt mendapatkan hasil yang akurat karena kecenderungan ibu hamil menderita pre-eklampsia diperiksa melalui tekanan pembuluh darah ibu dan plasenta. Kelebihan pemeriksaan skrining pre- 
eklampsia USG DVAUt yang lainnya adalah peralatan yang digunakan untuk pemeriksaan lebih canggih dibandingkan dengan alat sonografi yang biasanya digunakan. Alat sonografi yang digunakan untuk USG DVAUt lebih canggih dan dilengkapi fitur yang berbeda sehingga dapat mendeteksi kecenderungan ibu hamil menderita pre-eklampsia serta mendeteksi kelainan pada janin dengan ibu kecenderungan pre-eklampsia secara mendetail. Selain itu kelebihan skrining pre-eklampsia USG DVAUt lainnya adalah pelaksana skrining pre-eklampsia USG DVAUt adalah dokter spesialis kandungan yang berkompeten dalam melaksanakan skrining pre-eklampsia dengan alat sonografi USG DVAUt. Untuk mengoperasikan alat sonografi USG DVAUt berbeda dengan alat pemeriksaan sonografi yang biasanya digunakan untuk pemeriksaan kandungan pada umumnya.

Pemeriksaan skrining pre-eklampsia USG DVAUt juga memiliki kekurangan, diantaranya adalah untuk mengikuti pemeriksaan skrining pre-eklampsia USG DVAUt ini dikenakan biaya yang cukup besar. Biaya yang dikenakan lebih mahal dari pemeriksaan ultrasonografi kandungan biasanya karena alat yang digunakan untuk pemeriksaan skrining pre-eklampsia USG DVAUt lebih mahal dan jarang ditemukan di tenpat pelayanan kesehatan pada umumnya. Alat USG DVAUt yang mahal ini menyebabkan tidak semua tempat pelayanan kesehatan dapat melakukan pemeriksaan skrining pre-eklampsia USG DVAUt. Tempat pelayanan kesehatan dengan alat sonografi USG DVAUt akan membutuhkan alat sonografi yang khusus digunakan untuk pemeriksaan DVAUt dan petugas pelaksana atau petugas pengoperasi alat USG DVAUt yang berpengalaman dan berkompeten. Petugas pelaksana atau petugas pengoperasi alat sonografi USG DVAUt dibutuhkan yang berpengalaman dan berkompeten dalam mengoperasikan alat sonografi.

Petugas yang kurang kompeten dan kurang pengalaman dalam mengoperasikan alat sonografi dikhawatirkan akan menyimpulkan hasil skrining pre-eklampsia yang kurang akurat sehingga hasil pemeriksaan skrining pre-eklampsia ibu hamil tidak mampu mencerminkan uji diagnostik yang tepat dan akurat dalam deteksi dini pre- eklampsia. Hasil deteksi dini pre-eklampsia yang kurang tepat dikhawatirkan menyebabkan ibu hamil yang seharusnya mendapat penanganan lanjut atau terapi atas hasil pemeriksaan dengan kecenderungan pre-eklampsia menjadi luput dari terapi. Ibu hamil dengan kecenderungan pre-eklampsia yang tidak mendapat terapi dikhawatirkan akan mengalami pre-eklampsia pada kehamilan atau persalinan ataupun masa nifas. Penanganan yang kurang tepat atau cenderung terlambat dalam pre-eklampsia juga akan menyebabkan terjadinya komplikasi pada ibu maupun janin yang dikandung.

Pemeriksaan skrining pre-eklampsia USG DVAUt akan menghasilkan data skrining preeklampsia yang akurat jika dilaksanakan oleh petugas pelaksana atau petugas pengoperasi yang berpengalaman dan berkompeten dalam pelaksanaan pemeriksaan skrining pre-eklampsia pada ibu hamil. Petugas pelaksana atau petugas pengoperasi alat sonografi USG DVAUt adalah dokter spesialis kandungan yang sudah dilatih untuk mengoperasikan alat sonografi DVAUt. Pemeriksaan skrining pre-eklampsia yang kurang akurat mampu mempengaruhi hasil sensitivitas dan spesifisitas pemeriksaan skrining preeklampsia dalam deteksi dini pre-eklampsia pada ibu hamil.

Pelatihan seorang dokter spesialis kandungan untuk mengoperasikan alat USG DVAUt memerlukan waktu tertentu dan biasanya dilaksanakan di Rumah Sakit Umum Dr Soetomo Surabaya. Pemeriksaan skrining pre-eklampsia USG DVAUt dimulai dilaksanakan Rumah Sakit Umum Dr Soetomo Surabaya yang kemudian diikuti oleh rumah sakit lainnya di Surabaya.

Kepedulian masyarakat akan pre-eklampsia dan tanda bahaya kehamilan menjadi salah satu pemicu semakin banyaknya tempat pelayanan kesehatan yang melakukan skrining preeklampsia pada ibu hamil di rumah sakit atau puskesmas maupun klinik kesehatan lainnya. Sebagian besar tempat pelayanan swasta yang menyediakan pemeriksaan skrining pre-eklampsia memiliki biaya yang sulit dijangkau masyarakat. Tempat pelayanan kesehatan dengan pemeriksaan skrining pre-eklampsia yang terjangkau adalah tempat pelayanan kesehatan milik pemerintah. 
Tempat pelayanan kesehatan dapat mempengaruhi hasil sensitivitas dan spesifisitas pemeriksaan skrining pre-eklampsia. Tempat pelayanan yang memiliki alat USG DVAUt jumlahnya sedikit. Alat USG DVAUt yang baik akan memberikan hasil pemeriksaan skrining pre-eklampsia yang akurat dan tepat. Hasil skrining pre-eklampsia yang akurat dan tepat akan memberikan penanganan yang tepat juga untuk melakukan penanganan selanjutnya pada ibu hamil yang ditemukan dengan kecenderungan pre-eklampsia.

\section{SIMPULAN DAN SARAN}

\section{Simpulan}

Pemeriksaan skrining pre-eklampsia dengan USG DVAUt memiliki tingkat sensitivitas dan spesifitas yang cukup tinggi. Sensitivitas sebesar $99.7 \%$ memiliki arti bahwa pada 100 ibu hamil yang dilakukan pemeriksaan skrining pre-eklampsia akan memberikan hasil yang akurat dan benar pada pemeriksaan sejumlah 99 ibu hamil. Spesifisitas sebesar $81,9 \%$ berarti bahwa pada 100 ibu hamil yang dilakukan pemeriksaan skrining pre-eklampsia akan memberikan hasil yang akurat dan benar pada 81 ibu hamil. Pemeriksaan skrining pre-eklampsia menggunakan USG DVAUt memiliki validitas tinggi karena nilai sensitivitas dan spesifitas tinggi.

\section{Saran}

Melakukan pelatihan pemeriksaan skrining pre-eklampsia. Melakukan penelitian lebih mendalam tentang metode USG DVAUt untuk skrining pre-eklampsia. Melakukan penjadwalan ibu hamil untuk mengikuti USG DVAUt secara teratur.

\section{DAFTAR PUSTAKA}

Abdul, 2006. Penanganan Preeklamsia. Jakarta: Arean.

Antsaklis, A., Daskalakis, G., 2010. Uterine Artery Doppler in the Prediction of Preeclampsia and Adverse Pregnancy Outcome. Donald School Journal of Ultrasound in Obstetrics \& Gynecology, 4(2), pp.117-122.
Budiarto, E., 2012. Metodologi Penelitian. Jakarta: Penerbit Buku EGC.

Dahlan, M., 2009. Penelitian Diagnostik: DasarDasar Teoretis dan Aplikasi dengan Program SPSS dan Stata. Jakarta: Salemba Medika.

Depkes RI, 2006. Profil Kesehatan Indonesia Tahun 2004. Jakarta: Departemen Kesehatan Republik Indonesia.

Dewi, G.A.I., Sulistiyono, A., Mahmudah, 2015. Analisis Faktor yang Berpengaruh terhadap Kemampuan Ibu Hamil dalam Melakukan Deteksi Dini Risiko Perdarahan Pasca Persalinan dan Preeklamsia. Majalah Obstetri \& Ginekologi, 23(2), pp.49-53.

Dinkes Provinsi Jawa Timur, 2018. Profil Kesehatan Provinsi Jawa Timur Tahun 2017. Surabaya: Dinas Kesehatan Provinsi Jawa Timur.

Doenges, M.E., Moorhouse, M.F., Geissler, A.C., 2012. Rencana Asuhan Keperawatan: Pedoman untuk Perencanaan dan Pendokumentasian Perawatan Pasien. Jakarta: Penerbit Buku Kedokteran EGC.

Kemenkes RI, 2014a. Hipertensi. Jakarta: Kementerian Kesehatan Republik Indonesia.

Kemenkes RI, 2014b. Mother's Day: Situasi Kesehatan Ibu. Jakarta: Kementerian Kesehatan Republik Indonesia.

Maryunani, A., Yulianingsih, 2012. Asuhan Kegawatdaruratan dalam Kebidanan. Jakarta: Trans Info Media.

Panuluh, S., Fitri, M.R., 2016. Perkembangan Pelaksanaan Sustainable Development Goals (SDGs) di Indonesia. Jakarta: International NGO Forum on Indonesian Development.

Pepe, M.S., Janes, H., Longton, G., Leisenring, W., Newcomb, P., 2004. Limitations of the Odds Ratio in Gauging the Performance of a Diagnostic, Prognostic, or Screening Marker. American Journal of Epidemiology, 159(9), pp.882-890.

Prawirohardjo, S., 2013. Ilmu Kebidanan. 4th ed. Jakarta: PT Bina Pustaka Sarwono Prawirohardjo.

Putra, A.N.E., Hasibuan, S., Fitriyati, Y., 2016. Hubungan Persalinan Preterm pada Preeklampsia Berat dengan Fetal Outcome di RSU Islam Harapan Anda Tegal. Jurnal 
Kedokteran dan Kesehatan Indonesia, 6(3), pp.113-119.

Sciscione, A.C., Hayes, E.J., 2009. Uterine Artery Doppler Flow Studies in Obstetric Practice. American Journal of Obstetrics and Gynecology, 201(2), pp.121-126.

Sibai, B.M., 2013. A Stepwise Approach to Managing Eclampsia and Other Hypertensive Emergencies. OBG Management, 25(10), pp.35-48.
The American College of Obstetricians and Gynecologists, 2013. Hypertension in Pregnancy. Hypertension in Pregnancy. Washington, DC: The American College of Obstetricians and Gynecologists.

The Society of Obstetricians and Gynaecologists of Canada, 2016. ALARM (Advances in Labour and Risk Management) Course Manual 22nd Edition - 2015-2016. Canada: SOGC. 